\title{
VERZEICHNIS UNÜBLICHER, IN DER ARBEIT VERWENDETER ABKÜRZUNGEN
}

\author{
Giese-Schunck \\ Friedrich Giese, Grundgesetz für die \\ Bundesrepublik Deutschland, 5.Aufl., \\ bearbeitet von Egon Schunck, Frankfurt \\ a. M. 1960 \\ Hueck, Lehrbuch des \\ Arbeitsrechts, Bd.I \\ v. Mangoldt-Klein \\ Maunz-Dürig \\ Nawiasky-Lechner \\ Nawiasky-Leusser \\ Nipperdey, Lehrbuch \\ des A rbeitsrechts, \\ Bd. II \\ Reinhardt, Verfas- \\ sungsschutz des \\ Eigentums \\ Scheuner, Verfas- \\ sungsschutz des \\ Eigentums \\ Alfred Hueck und Hans Carl Nipperdey, \\ Lehrbuch des Arbeitsrechts, 6.Aufl., \\ Bd. I, Berlin/Frankfurt a. M. 1959 \\ Helmut v. Mangoldt, Das Bonner Grund- \\ gesetz, 2.Auf1., bearbeitet von Fried- \\ rich Klein, Berlin/Frankfurt a. M. \\ $1955 \mathrm{ff}$ \\ Theodor Maunz und Günther Dürig, \\ Grundgesetz, München/Berlin 1958 ff \\ Hans Nawiasky und Hans Lechner, Die \\ Verfassung des Freistaates Bayern, Er- \\ gänzungsband zum Handkommentar, \\ München 1953 \\ Hans Nawiasky und Claus Leusser, Die \\ Verfassung des Freistaates Bayern, Sy- \\ stematischer Überblick und Handkom- \\ mentar, München/Berlin 1948 \\ Alfred Hueck und Hans Car1 Nipperdey, \\ Lehrbuch des Arbeitsrechts, 6. Auf1. , \\ Bd. II, Berlin/Frankfurt a. M. 1957 \\ Rudolf Reinhardt und U1rich Scheuner, \\ Verfassungsschutz des Eigentums, \\ Tübingen 1954, S. $1-62$ \\ das. S. $63-162$
}


